Revista Estudios, (37), 2018.

Diciembre 2018-Mayo 2019

ISSN 1659-3316

Cambronero Torres Andrei

IV Sección: Sociedad, vida política e historia

\title{
¿QUO VADIS SOCIEDAD? \\ Una radiografía del espacio social en el que estamos viviendo
}

\author{
Andrei Cambronero Torres \\ acambronero@tse.go.cr \\ Tribunal Supremo de Elecciones (TSE), Costa Rica \\ https://orcid.org/0000-0002-1768-6921
}

Recibido: 10 de setiembre de 2018

Aceptado: 30 de setiembre de 2018

Resumen: El artículo evidencia algunas particularidades que, en la actualidad, tiene la sociedad. Ese concepto clásico de la teoría social hoy, al igual que todo aquello que parecía robusto, suele presentarse desdibujado: la incertidumbre también ha tocado el objeto de la Sociología. El texto se encuentra estructurado en cuatro apartados; el primero de ellos, supone un bosquejo de cuáles son algunas características del orden social actual para, luego, presentar desafíos que, desde las Ciencias Sociales, tiene esa nueva estructuración. De seguido, se exponen tres conceptos relativamente novedosos con los que se facilita la comprensión de las dinámicas contemporáneas para, finalmente, hacer una breve determinación de los atributos de la sociedad en la que estamos viviendo.

Palabras clave: Sociedad; dinámicas sociales; sociología contemporánea; orden social.

\section{QUO VADIS SOCIETY? An X-ray of the social space in which we are living}

Abstract: The article evidences some of the particularities society possesses in actuality. That classical concept of the social theory appears today, just like everything that seemed strong, blurred: the uncertainty has also touched the object of Socioglogy. This text finds itself structured in four sections; the first is a sketch of what are some characteristics of the current social order to present the challenges, that from the Social Sciences, this new structure has. Then, three relatively new concepts are presented, which facilitate the understanding of contemporary dynamics and finally, there's a brief description of the attributes of the society.

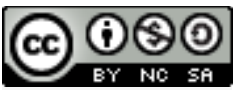

La Revista Estudios es editada por la Universidad de Costa Rica y se distribuye bajo una Licencia Creative Commons Atribución-NoComercial-CompartirIgual 3.0 Costa Rica. Para más información envíe un mensaje a revistaestudios.eeg@ucr.ac.cr. 
Key words:Society; Contemporary sociology; social order.

\section{CUESTIONES LIMINARES}

Incertidumbre, un horizonte nublado, se rompe el pacto de una tierra prometida de progreso para creyentes y profanos, la brújula se ha desimantado y se torna errática; cual si se tratara de la frase marxista inmortalizada por sí, pero también en la obra de Berman (2013), todo lo sólido se desvanece en el aire. El señorío que, de forma real o percibida, se tenía sobre el mundo empieza a perderse y los centros de imputación (cuando no de reclamo) se dispersan y, en muchas ocasiones, se tornan invisibles.

Ese panorama -para muchos gris- está mediado por condicionamientos políticos y económicos que, con el advenimiento de este nuevo siglo, han generado dinámicas cuyas denominaciones varían según el autor, pero que -en un tono elocuente- Sassen (2015: 91-94) llama "formaciones predatorias", como el resultado de la combinación de las élites con las capacidades sistémicas que tienen, a las finanzas, como posibilitador clave de la concentración aguda. En otros términos, la concentración extrema de riqueza es posible gracias a una ayuda sistémica: interacción de individuos ricos o empresas globales con sistemas redirigidos a esa dirección específica (Sassen, 2015: 47-57).

Quizás la imagen de comer la manzana sea un cliché, mas -como alegoría- sí que ayuda a ejemplificar un sinnúmero de situaciones sociales. No hablaremos de las consecuencias éticas o morales de sentirse desnudos, tampoco si la responsabilidad vino de "uno" o "una", el punto es que, como grupo, en algún punto dimos el mordisco y, en el primer bocado, nos dimos cuenta de nuestras diferencias. La distribución social del trabajo, poseedores y desposeídos, clases, estratos, entre otros conceptos que, en una visión muy simplista, nos exponen

\section{(c) (i) (2)}

La Revista Estudios es editada por la Universidad de Costa Rica y se distribuye bajo una Licencia Creative Commons Atribución-NoComercial-CompartirIgual 3.0 Costa Rica. Para más información envíe un mensaje a revistaestudios.eeg@ucr.ac.cr. 
diferenciaciones entre los individuos, nos dicen que casi siempre (por no ser absolutistas en la formulación) ha existido desigualdad. Sin embargo, la “concentración aguda" de capitales -como lo indica la socióloga neerlandesa- ha alcanzado niveles sin precedentes.

Frente a ese panorama, habría que preguntarse cuáles han sido las condiciones de posibilidad que nos colocaron, como se sienten no pocos, al borde del precipicio. Las explicaciones en punto a ese tópico son variadas y el acento es dado según quien investiga o escribe; empero, al menos desde Nachtwey (2017), Streeck (2016) y la citada Sassen (2015), la pauperización ha sido el resultado de cambios en la dinámica de los mercados y el capitalismo tardío que, luego de la segunda posguerra, se empezaron a dar.

La reconstrucción y cese de las hostilidades trajeron consigo políticas que, si bien no acabaron con la desigualdad o el racismo, sí que generaron un ambiente propicio para fortalecer la producción y el consumo masivos, con sindicatos vigorosos que luchaban por mantener el poder adquisitivo de los salarios y el pleno empleo. No obstante, en los años ochenta del siglo anterior, se da un viro o reestructuración hacia un capitalismo favorable políticas económicas desregulatorias, la privatización de servicios y la eliminación de los aranceles a las importaciones (Sassen, 2015).

Tales condiciones (propias de un paradigma neoliberal), son, a decir de Streek (2016, pp. 17-21), el resultado de una rebelión del capital de las "ataduras" y "jaulas" en las que se le había recluido luego de mediados de la década de 1940; esa liberación fue posible de la mano de una lealtad de las masas al proyecto social cuyo estandarte es el consumo.

Ante esa sensación de vértigo, de estar en medio de la vorágine, en las siguientes líneas se desarrollará cuál es el "orden” social contemporáneo, para de seguido- exponer algunos retos que -en ese nuevo marco- tiene la Sociología como disciplina cuyo objeto es, precisamente, la cambiante sociedad; luego, se expondrán tres conceptos con bondades explicativas para los fenómenos de hoy 
$y$, finalmente, se hará un recuento de cinco grandes especificidades del mundo social en el que nos toca vivir.

\section{ORDEN SOCIAL CONTEMPORÁNEO: EN VERDAD, ¿UN ORDEN?}

Ante el marco general esbozado, vale preguntarse cuál es el orden social en el que nos desenvolvemos. Claro, de previo a esa interrogante, habrá que dar por sentada la existencia del orden mismo pues, caso contrario, sería un sinsentido. Pese a corrientes sobre el caos (fragmentos sin relación a sugerencia de los posmodernistas), nos decantamos por una organización de las dinámicas sociales; tributarios del planteamiento de Dubet (2009), en su obra El trabajo de las Sociedades, afirmamos que, pese a las grandes transformaciones de las últimas décadas, sigue existiendo una fuerza que nos modela y condiciona, ya no con su antigua "morfología" o con una estructura de clases capaz de "explicarlo todo", pero sí a cuenta de un sistema general: la sociedad.

En otras palabras, los acomodos y reacomodos contemporáneos no antagonizan con el orden sino, antes bien, lo resemantizan y generan uno nuevo que, por particular, todavía a algunos les parece que no hay tal; ellos solo reconocen un estado caótico de cosas. Entonces, si no hemos de "tirar al niño con el agua sucia" (Dubet, 2009 pp. 51-54) y comprendemos el valor analítico tiene la sociedad como concepto, debe aceptarse la existencia de un orden, hilos aglutinadores de partes que, en lo superficial, parecieran no tener sentido alguno.

En primer término, la disposición de referentes económicos y políticos (nación y soberanía incluidos) ha roto el espacio territorial clásico: el país. La aparición de mercados globales, dinámicas de consumo de esa misma escala, la modernización y, en especial, los flujos financieros han desplazado las grandes decisiones del Estado a grupos económicos o entidades internacionales que fijan las pautas de inversión, empleo y, en suma, de calidad de vida. En un paradigma de posdemocracia, esto es una disminución sostenida de la capacidad real de los 
ciudadanos para incidir en las políticas públicas (pese al paradójico aumento en los mecanismos de participación), el control viene de los lobbies, las élites económicas y las multinacionales (Nachtwey, 2017, pp. 71-75).

Ciertamente, a lo largo de la historia, se han configurado grupos en los que se deposita la capacidad de generar las reglas sociales en el plano formal. Usualmente, en la partitura del Estado moderno, se piensa en los parlamentos como órganos estatales con la legitimación necesaria y suficiente para estatuir cómo habrá de organizarse la vida entre los individuos, aunque -en el plano realen ese proceso de fabricación de ley (como producto característico de tales instancias) inciden conglomerados con intereses sectoriales. La Ciencia Política está consciente de ello y, por ejemplo, se ocupa de las dinámicas de organización del poder no solo en el plano institucional, sino también en esos intercambios reales cuyos resultados encausan las decisiones en uno $u$ otro sentido; como una muestra de lo expuesto, evóquese la tradicional distinción conceptual entre forma de gobierno, régimen político y sistema político.

En los tiempos que corren, si el Derecho aspira a mantenerse como uno de los agentes reguladores $-y$ de ordenación de primera línea- debe resemantizarse. El principio de territorialidad, según el cual la norma jurídica aplicable es la del país en la que se dio el hecho dañoso, ha ido perdiendo la primacía con la que gozaba; aparecen hoy regulaciones supranacionales e instancias de resolución de conflictos de escala superior. Los problemas o desavenencias en los intercambios comerciales se dirimen en foros de arbitraje e instancias de tutela modelan las matrices axiológicas de los países en pro de una ética universal: los derechos humanos.

Así, el orden actual se mueve en planos: lo nacional vs lo foráneo, donde este último influye -principalmente por medio de políticas económicas fijadas en los centros de capital- en cómo se disponen las estructuras sociales en ese orden global. En suma, en el siglo XXI se consolida la sociedad mundial como un análogo del mercado mundial, lo cual supone modelos abstractos expresados en 
función de los niveles constitutivos de las relaciones sociales. Acá las fronteras internas se desdibujan y las solidaridades se desplazan (Outhwaite, 2008).

Hace algunas líneas se señalaba cómo en las condiciones actuales, se favorecía la aparición de espacios de participación ciudadana, aunque su peso real fuera ínfimo; en similar sentido, se indicaba que las ganancias crecían, pero las condiciones generales de bienestar van a la baja y al alza las desigualdades; se sostiene la bandera de un culto a la individualidad, mas las cotas estructurales niegan tal condición a un número creciente de personas... O sea, el orden actual es altamente contradictorio.

El cracking cultural, que se identifica con una sociedad de masas (típica del actual período), difunde e impulsa el consumo de bienes concretos como la vía para la obtención de cierto estatus o reconocimiento social; sin embargo, las especificidades de una modernidad regresiva (Nachtwey, 2017, pp. 59-92) trocan las condiciones de trabajo a unas de índole precaria en las que el ingreso no se corresponde con las necesidades de subsistencia, pero que, además, se vuelven cómplices del estancamiento y ya no aseguran el ascenso; antes bien, parecen una patente de corso al descenso.

Con esas limitaciones estructurales, el individuo que, por las expectativas actuales, debe consumir suele hacerlo a costa de su deuda privada: pide créditos para las "grandes" conquistas personales, como también para las pequeñas, obligaciones que -luego- no tiene plena capacidad de honrar y sobreviene la frustración. Si se toma una postura teorética como la de Žižek (2008), hay que reconocer la incapacidad actual para que se generen dinámicas aglutinadoras cuasi totalizantes como sí ocurría en el pasado (una nación robusta en la que "cabían" todos, por ejemplo), eso promueve el surgimiento de subculturas a las que se pertenece por la capacidad de comprar bienes asociados a ellas; así, cuando un sujeto se identifica con uno de eso "grupos" pero no tiene los medios materiales para acceder a los elementos que le harían formar parte, se siente presa de infortunio, ha sido expulsado a decir de Sassen (2015).

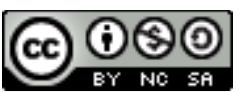

La Revista Estudios es editada por la Universidad de Costa Rica y se distribuye bajo una Licencia Creative Commons Atribución-NoComercial-CompartirIgual 3.0 Costa Rica. Para más información envíe un mensaje a revistaestudios.eeg@ucr.ac.cr. 
De otra parte, ese orden social multinivel y contradictorio es a su vez frágil. Si se parafrasea a Trosky, diríamos que el orden social -hasta las postrimerías del siglo XX- fue solvente en hacer ver una suerte de imposibilidad de las "revoluciones" $y$, por ende, afianzaba una capacidad para desarmar la "inevitabilidad del conflicto". Es claro que en la etapa anterior se dieron enfrentamientos y relaciones tensionadas, desde la Guerra Fría hasta los gobiernos autoritarios de izquierdas y derechas (principalmente en América Latina) dan testimonio de ello; además, la Sociología también se ocupó de teorías del conflicto y sus aportes al cambio social (en este sentido, puede consultarse a Rex, 1981). No obstante, la estructura de clases, el Estado y sus agencias como centros de imputación y un respaldo mayoritario a la institucionalidad en el mundo occidental daban estabilidad al mundo social.

Actualmente, esa solidez está contradicha, la posibilidad de que se configuren movimientos espontáneos para hacer un reclamo y hacer sentir, incluso de manera violenta, un descontento para estar dada en cualquier momento. Una estampa de lo indicado se encuentra en Nicaragua: en junio de 2018, a poco menos de tres meses de enfrentamientos entre la población y la élite política (acomodaticia a otro tipo de intereses, como los económicos), no parecía que, seis meses atrás, alguien hubiera previsto lo álgido de esa situación.

Por ello, son necesarios mecanismos de legitimación constantes, rasgos de aceptación del sistema o, como invoca Streek a Adorno, incentivos para la sensación de bienestar en alienación (Streek, 2016, pp. 30-32); el referido impulso a la individualidad es una de esas estratagemas: si se desciende es porque el individuo por sí no ha sido capaz de mantenerse a flote y, consecuentemente, el único responsable de su desgracia.

Tales escarceos, como se decía, no están siendo capaces ya de mantener la solidez del orden; todos los días aumenta la probabilidad de que aparezca una "amenaza" que comprometa el cada vez menos estable mundo social. La incertidumbre que ello genera, sumada al descontento, la sensación de amenaza y 
la desconfianza de que el otro pueda despojarme de lo poco que tengo, de mi pequeña parcela de estabilidad, son el caldo de cultivo para los extremismos: como efecto colateral, la dinámica social actual parece fomentar las posturas radicales.

En ese sentido, vale indicar que el discurso antipolítica -en el plano latinoamericano- ha sido terreno fértil para el desarrollo de caudillismos que enarbolan la bandera del pueblo; en consecuencia, se da paso a protagonistas con un ropaje mesiánico, a quienes se les otorga una autorización tácita para el salvamento, con la opción de fugarse de la democracia por intermedio de mecanismos democráticos (iparadoja!). Ese panorama, que debe llamarnos a la reflexión, puede contratacarse si, como ocurría antes, se fortalece la institucionalidad y su confianza en ella.

Bascuñán y Vallespín (2015) indican que el contexto para la concreción de un bloque de víctimas de la negatividad del sistema (como motor de los populismos) es la aparición de demandas insatisfechas; de acuerdo con ello, cabe preguntarse $\mathrm{si}$, entonces, en las regiones con mayores índices de pobreza, balanzas de pago y comercial deficitarias y complicaciones fiscales están destinadas a la lucha impulsada por los populismos.

Si es así, cuáles podrían ser las vías -con posibilidades reales de implementación- para "frenar" el fenómeno en tales sitios. De otra parte, es necesario explorar aspectos propios de cultura política que llevan, incluso en esos escenarios económicos adversos, a no aceptar la invitación a gobiernos de personas representantes "legítimas" del pueblo.

En similar sentido, queda abierta la incógnita de si, a futuro, lo que hoy no es una ideología (sino más bien una forma de acción política, como lo aclaran los citados autores) tenga el desarrollo teórico, la reflexión y los elementos necesarios para convertirse en tal y, entonces, reconocerla dentro del espectro político, ya no como un rasgo parasitario de otros discursos más elaborados, sino como una

\section{(c) (i) (2)}

La Revista Estudios es editada por la Universidad de Costa Rica y se distribuye bajo una Licencia Creative Commons Atribución-NoComercial-CompartirIgual 3.0 Costa Rica. Para más información envíe un mensaje a revistaestudios.eeg@ucr.ac.cr. 
manifestación autónoma de las dinámicas de poder o, como indican los politólogos, del sistema político contemporáneo.

En una palabra, el orden social actual se mueve en diversos planos de forma paradójica con una fragilidad patente y, en sí mismo, están presentes los mecanismos promotores de extremismos. Para decirlo de otro modo, Estado, estructura, clase y lo social han adquirido nuevos matices y la sociedad de los Sociólogos (Dubet, 2009, pp. 19-54), como categoría analítica compuesta, debe embarcarse en la travesía de repensar sus contenidos.

\section{DESAFÍOS EN UN ORDEN SUI GENERIS}

Ante esa invitación a reformular la perspectiva teórica de la Sociología deben reconocerse los retos que, para llevar a cabo tal objetivo, se tienen. En primera instancia, como ya lo hace ver Dubet (2009), las desigualdades han dejado de constituir un sistema funcional y las clases (como bloques compactos, homogéneos a su interior) ya no forman sociedad; las quejas ya no encuentran un destinatario concreto y todo parece desvanecerse. Ese "ocultamiento" de la estructura parece cerrar una puerta, la ambición explicativa sobre un sistema objetivo de leyes por definir se ha abandonado, en tanto las apariencias hacen creer que tal objeto ya no existe más.

Para utilizar una metáfora caricaturesca, que el comediante argentino Enrique Pinti aplica a la democracia, la "sociedad ha sido como la saliva": todo el mundo la tiene en la boca, pero nadie sabe de dónde viene y muy pocos para lo que sirve. Precisamente, el papel de los sociólogos, en mucho, ha consistido en indagar cuáles son las condiciones sociales de posibilidad que favorecen la ocurrencia de tales o cuales fenómenos y con qué hilos se encuentran amarrados los individuos en sus interacciones.

A la par de esto, debe señalarse que, como lo explicita el mentado sociólogo francés, ha habido un acuerdo tácito acerca de la existencia de la

La Revista Estudios es editada por la Universidad de Costa Rica y se distribuye bajo una Licencia Creative Commons Atribución-NoComercial-CompartirIgual 3.0 Costa Rica. Para más información envíe un mensaje a revistaestudios.eeg@ucr.ac.cr. 
sociedad; si bien tal pacto se ha matizado según se siga el holismo o individualismo, lo cierto es que -inequívocamente- se le acepta como una representación externa de los sujetos que, en gran medida, los condiciona.

Así, las variaciones de la vida social deben ser estudiadas y tratados de explicar sus causas y efectos. Ciertamente, la idílica sociedad en orden, con pocas disrupciones en lo cotidiano, parece ser rara avis; además, los centros de imputación se atomizan o vuelven invisibles. La sensación generalizada de no pertenecer a "ningún lugar" impera en el ambiente, mas lejos de ser esos elementos desmotivadores de la empresa sociológica, deben ser el acicate para profundizar en el análisis de lo que acontece.

En todo caso, dejar morir la sociedad es aceptar que la vida social, la acción colectiva y las significaciones fraguadas en grupo no son rasgos propios de nuestra especie; tal sentencia no solo va en contra de toda la experiencia acumulada hasta hoy, también nos coloca en el umbral de un abismo sin fondo donde la relación, como concepto y como vivencia, troca en una pieza de museo.

Otro de los retos de la disciplina es la globalización. Para decirlo con Outhwaite (2008, pp. 80-91), ese estadio último de un proceso de internalización presenta retos importantes para el análisis sociológico: presupone las metáforas de red y flujo, más que de región o terreno estable. En ese tanto, los grupos son más informales y transitorios, no hay jerarquías formales, con lo que se da, además, una ampliación de las formas para integrarse en el sistema.

Lo expuesto, como bien lo explicita el sociólogo inglés, tiene relación con lo comentado acerca de la flexibilidad del concepto "sociedad". La Sociología debe ser capaz de entender los nuevos entramados de relaciones y cómo estos inciden en la generación de un espacio social común, al tiempo que posibilitan la heterogeneidad de los grupos. Una de las formas en que eso es viable es afirmando, como Luhmann (2006), la sociedad como un sistema de sociedades.

Esa respuesta teórica, se comparta o no, supone una representación del entorno en el que desenvuelven hoy los individuos, sea es una pretensión de dar 
sentido a lo social como una necesidad de esos sujetos (aunque, en tal entramado teorético, estén negados). Para exponerlo según lo hace Dubet (2009, pp. 52-53), los sociólogos deben participar en la reflexión contemporánea produciendo representaciones; para decirlo en breve, ante los múltiples cambios que se experimentan, se debe brindar sosiego a las inquietudes y sobresaltos que están produciendo las dinámicas sociales.

Eso sí, para lograr acometer con éxito el reto se debe -una vez más- tomar distancia del objeto y seguir los consejos de los padres fundadores en punto a dejar de lado las prenociones (Durkheim, 2011), pero -en este caso- sería de las prenociones de los contenidos tradicionales de los conceptos: la labor justamente es reajustar las categorías, por lo que el análisis no puede verse limitado por las cotas acostumbradas.

Ahora bien, sin ser exhaustivos ni pretender agotar la enumeración de todos los desafíos, el lente debe ajustarse en lo que a las subjetividades respecta. La tensión macro-micro se ha evidenciado con mayor énfasis en la tradición sociológica angloamericana; la inquietud de cómo se pasa de lo individual a lo social o de lo social a lo individual -en esa corriente- ha generado no pocos debates, de la mano con la aparición de teorías y planteamientos como el estructural-funcionalismo o el interaccionismo simbólico, sin dejar de lado célebres en la disciplina tales como La construcción social de la realidad de Berger y Luckmann (1995).

Este no resulta ser el espacio propicio para desarrollar la -valga decirinteresante propuesta teórica aludida en el párrafo anterior, ni para bosquejar si la apuesta la gana el todo o la parte. Lo imprescindible es reconocer que el oficio del sociólogo apunta a intuir dónde están los lazos que unen un extremo con el otro, ligámenes que, como se ha venido exponiendo, han ido variando en su configuración.

Con las miras puestas en ese horizonte y ante las apreciaciones de índole más macro de las que ha hecho mención, conviene indicar que las condiciones 
actuales llevan a una dinámica entre la apertura a nuevas subjetividades y el surgimiento de fundamentalismos identitarios; la adscripción de los individuos a esas estructuraciones sencillas que pintan un mundo maniqueo (nosotros o contra nosotros), se da en tanto se conciben como válvulas de escape: liberan de la angustia y fatiga de ser alguien desposeído, a punto de ser expulsado o un acérrimo usuario de la escalera eléctrica hacia el piso de bajo, para utilizar la figura de Nachtwey (2017, pp. 120-124).

Como lo advierte Kaufman (2015:36-37), el individuo moderno multiplica sus "microcompromisos"; cuantos más "sí mismos" posibles, más breves y efímeras resultan ser las adscripciones a grupos totalizantes (categorías que antes eran la base principal de análisis). De hecho, esa relación se refleja en cómo, en sociedades tradicionales, el tema de la identidad no es un problema: el sentido de la vida viene dado por la realidad objetiva y el marco institucional. O sea, el problema del ser era resuelto por la estructura externa al sujeto.

En contraposición, cada vez más frecuentemente tenemos que el individuo no pertenece a tal o cual grupo, más bien decide inscribirse en él por el tiempo necesario según su entendimiento. La persona, entonces, no se define por sus adscripciones más que en la medida en que las reactiva y hace ostentación de ellas. Dicho de otro modo, hay una tensión entre el individuo autónomo y la integración colectiva; esta última, en lo contemporáneo, se denota con pertenencias cada vez más pasajeras y marcos objetivos cada vez más abstractos y volátiles (Kaufman, 2015, pp. 37-40).

En un mundo que se presenta cada vez más complejo, ingrato y mezquino con dotar de herramientas para darle sentido a la vida, los sujetos se enfrentan a una sensación de desolación. Frente a ello, cualquier empresa contra la labilidad y contingencia parece un remanso, lugar propicio para guarecerse, para pertenecer.

Sin embargo, esas pequeñas porciones de tierra forman -si acaso- un archipiélago inestable, en el cual se puede estar, pero por poco tiempo. La inexistencia de lazos fuertes - producto de una carestía de características 
compartidas- hacen que la acción social sea efímera con manifestaciones espasmódicas en favor o en contra de algo específico; desaparecido el elemento aglutinador, desaparece también el engrudo y cada quien vuelve a sentirse solo, abandonado.

Ese panorama poco motivador, sumado a la propuesta de entender la identidad como un aspecto de subjetividades más que un determinismo sociohistórico, vuelven a dar vitalidad a las preguntas fundamentes de las más rancias tradiciones filosófica y de teoría social, interrogantes que vale la pena reseñar: El concepto de clase, ¿debe re-encuadrarse para dar consistencia a nuevos grupos de experiencias disímiles y permitir un punto de encuentro? En un mundo caleidoscópico, ¿cuáles son los nuevos elementos definitorios del ser?, cuando el mundo del trabajo -en no pocos casos- copta la vida del individuo en su afán de ir tirando dentro de un marco mercantilizado.

Precisamente, contestar esas interrogantes suponen un espacio de profundización analítica que hoy debe ocupar a la Sociología; el típico individuo de clase se ha complejizado y con ello se impone la reestructuración de los estudios micro para, a la vez, generar radiografías más precisas de los conductos por los que transita la savia social.

\section{NUEVOS CONCEPTOS: UN PRIMER PASO HACIA LA COMPRENSIÓN}

Se han esbozado tres grandes retos para la disciplina sociológica con ocasión de las características del mundo contemporáneo; en esa línea, se considera oportuno ahora mostrar cómo, desde una tripleta conceptual, exponentes de la teoría social han iniciado la faena de construir categorías de análisis que permitan abordar -de manera solvente- lo que, en el último tiempo, ha estado ocurriendo.

La mercantilización de las dinámicas sociales ha originado una nueva forma de discriminación: el rechazo a quien no puede dejar dinero o a la persona cuya 
vida carece de valor. Esa es, justamente, la llaga en la que Cortina (2017) pone su dedo: existe una fobia al pobre que, como todas las animadversiones de ese tipo, se sustenta en una interiorización de que unos grupos son mejores que otros (relación asimétrica). En otras palabras, se da un rechazo a quien no puede ofrecer nada, a los peor situados (pobreza entendida como falta de libertad: imposibilidad de llevar a cabo planes de vida que la persona valora).

Con casi 25 años de historia (el término fue utilizado, por vez primera, en 1995), la aporofobia es un llamado de atención acerca de prácticas vejatorias, no contra un ente abstracto como "la dignidad humana" sino es el señalamiento de situaciones específicas de discriminación contra sujetos concretos.

El posicionamiento de filósofa española resulta sugerente. En sociedades en las que se potencia el uso de "democracia" -como concepto bandera- para legitimar muy diversas (cuando no antagónicas) acciones, se explicita cómo, pese a ser uno de sus presupuestos, el trato igualitario y la tolerancia están ausentes tratándose de los desposeídos.

Para su cometido, la autora centra su atención en mostrar la pertinencia de definir o, más preciso, de bautizar el fenómeno y, vale resaltar, se cuida de no caer en naturalismos lingüísticos: deja patente que la conceptualización es el primer paso, desde la teoría, para analizar el odio a la pobreza, pero -en simultáneo- está consciente de que eso no es suficiente.

Ahora bien, su propuesta de solución (respeto activo) tiene un fuerte componente ético que, como se reconoce en el texto, pasa por los procesos educativos; sin embargo, se deja de lado el impacto del modelo económico como generador de resistencias a tales cambios que -en todo caso- lo serían a largo plazo. En una región como la latinoamericana, con los mayores índices de desigualdad del orbe según CEPAL (2018), es necesario acompañar el replanteamiento de los modelos de enseñanza-aprendizaje con una intervención en los mecanismos de redistribución de la riqueza.

\section{(c) (i) (2)}

La Revista Estudios es editada por la Universidad de Costa Rica y se distribuye bajo una Licencia Creative Commons Atribución-NoComercial-CompartirIgual 3.0 Costa Rica. Para más información envíe un mensaje a revistaestudios.eeg@ucr.ac.cr. 
De igual modo, alguien podría apuntar que, como espacio de mejora, la aporofobia -como categoría analítica-parte de una visión iusnaturalista de los Derechos Humanos en la que no se aclara, de forma puntual, cuáles han de ser los mínimos para no deshumanizarse y por qué, en todo caso, esas prerrogativas han de ser concedidas y no otras. Asimismo, se asigna al Derecho una "función comunicativa", pero cabría preguntarse si, en términos generales, hay un conocimiento colectivo de las pautas jurídicas como premisa necesaria para la consecución de esa "veta pedagógica".

Pese a ello, lo cierto es que "aporofobia" resulta ser un referente con grandes bondades teórico metodológicas: permite llegar a las fibras y razones del rechazo de ciertos sujetos, aunque estos -en apariencia- pertenezcan a una misma categoría. Valiéndonos del ejemplo dado por la propia Cortina (2017, pp.11-16), diríamos que este constructo da las herramientas de comprensión para distinguir la aversión hacia los migrantes o desplazados (en los amplios términos de Sassen, 2015:75-91) frente a la fascinación por cierto turismo como el médico o el de jubilados de países de primer mundo. Igualmente, favorece el análisis de los reproches contra los "tomadores" del erario, sea quienes se "aprovechan" de los sistemas de salud, la educación, la asistencia social, etc. Esa objeción se funda, en mucho, en que se mira a quienes resultan destinatarios de esa intervención estatal como fracasados, individuos parasitarios por culpa de quienes la deuda pública y el déficit aumenta, pese a que, como bien lo sustenta Streeck, ese argumento no sea más que un distractor de las verdaderas causas: el paso de un pueblo del Estado a un pueblo del mercado.

Ese trance llamado Sociedad del Descenso (Nachtwey, 2017) o Segunda Modernidad (Kaufman, 2015 a partir de Giddens) encuentra en Castel (2010) una nueva etapa, la propicia para la aparición del individuo hipermoderno. Con la salvedad de que aún se está en una fase del "individuo moderno" como paradigma mayoritario (sujeto con derecho propio y autonomía que dispone de herramientas

\section{(C) $(0 \bigcirc$}

La Revista Estudios es editada por la Universidad de Costa Rica y se distribuye bajo una Licencia Creative Commons Atribución-NoComercial-CompartirIgual 3.0 Costa Rica. Para más información envíe un mensaje a revistaestudios.eeg@ucr.ac.cr. 
efectivas para desarrollar cierta independencia social), el recién citado sociólogo francés reconoce la pérdida de hegemonía de ese sujeto moderno.

Entre otras variables, la amenaza a la propiedad social facilita el surgimiento del individuo hipermoderno, una persona que puede permitirse ignorar que vive en sociedad: el sujeto está sumido en la subjetividad, pues todas las intervenciones sobre el otro y sobre sí mismo no tienen la finalidad de curar o reparar un déficit, sino de maximizar su propio potencial para ser más rico y productivo.

Precisamente, Castel (2010, pp. 303-338) descompone la indicada categoría en un individuo por exceso y otro por defecto. En el primer tipo se caracteriza por una demasía de subjetividad en la que no hay un encuadre (o lo hay muy poco) con regulaciones colectivas o aspiraciones de conjunto, su objetivo principal es realizarse como sujeto en solitario. La percepción de autosuficiencia (tener en sí mismo los soportes para la independencia social) lleva a desconocer los anclajes de grupo. Esta sería la figura del sujeto moderno en la modernidad tardía, una forma en la que quienes integran determinado grupo tienen los bienes y luces suficientes para bastarse solos.

Tal proposición permite comprender el nivel alto de competitividad que se vive en el mercado laboral, las extenuantes jornadas de trabajo a las que se sujetan jóvenes empresarios y la acumulación -en muy pocas manos- de gran parte de la riqueza. De hecho, la idea del emprendedurismo y ser "el propio jefe" no solo muestran el tipo de empleos y dinámica mercantil contemporánea, sino evidencia la reducción de espacios sociales (como anteriormente eran las fábricas tradicionales) y la indolencia hacia la situación adversa del otro.

En otro sentido, la categoría de individuo por exceso podría ser un referente óptimo para comprender manifestaciones sociales concretas como el grupo creciente de neosolteros, esto es personas que dentro de sus objetivos de vida no está el de tener una pareja estable, formar una familia y reproducirse; a decir de Alborch (1999), quien introdujo el término, esas personas son profesionales con 
alta cualificación, un nivel cultural considerable, muy competentes y con grandes ambiciones profesionales. Como puede observarse, hablamos de una categoría de sujetos cuyos intereses y autorrealización descansa en prácticas individuales.

Resulta oportuno apuntar que los individuos por exceso continúan dependiendo de lo social para realizarse, aunque en la configuración de su percepción de autosuficiencia esa idea no esté presente. De hecho, los parámetros según los cuales medirán su éxito están dados por la nueva configuración de la sociedad; tal rasgo, entonces, torna en paradójico el esquema actual: un sujeto que se "aísla" pero que, a la vez, depende de su entorno.

En la otra acera, los individuos por defecto están atrapados en la contradicción de no poder ser las personas que aspiran a ser. Se propugna por la libertad y la independencia (deseo generalizado de ser individuo), pero cada vez menos se cuenta con los elementos necesarios para llegar a alcanzar tales ideales. Cada quien vive a su manera la carestía y busca, de formas creativas, cómo salir de ella; sin embargo, no se logra, son individuos negados, en falta, sin posibilidad de lograr su cometido (Castel, 2010, pp. 326-333).

Latinoamérica siempre ha tenido grupos negados (indígenas, campesinos, migrantes, etc.), pero en una lógica homogénea, de conjunto. En la actualidad, a los miembros de esos colectivos se le adiciona una cantidad de personas de características muy diversas (heterogeneidad que impide hablar de un bloque compacto) que están viendo truncadas sus aspiraciones de ascenso social o que, estando en la carrera, un cambio o restructuración en su empresa los condena al desempleo $\mathrm{y}$, consecuentemente, a la frustración de no tener medios para mantener un nivel de bienestar. Al no compartir -los individuos por defecto-rasgos que puedan generar un vínculo capaz de unirlos para emprender transformaciones conjuntas, se crean -cual círculo vicioso- las condiciones para mantener el precariado, como le denomina el escritor del Ascenso de las incertidumbres.

Esa incerteza nos lleva, de forma directa, al tercer concepto que, según nuestro criterio, tiene amplias posibilidades explicativas en las estructuraciones 
sociales contemporáneas. La retrotopía de Bauman (2017) invoca el deseo de volver a zonas seguras, estables, en las que se tenía un dominio del presente y el futuro era promisorio; la sociedad actual tiene como elementos distintivos la soledad y el miedo a ella, estos son sentimientos generalizados, pero simultáneamente- hechos objetivos de la modernidad líquida. La transitoriedad se apropia de las relaciones y hay un desvanecimiento de los lazos interpersonales, nada significa lo que significó en su momento.

Por ello, es claro que la hoja de ruta es ahora inversa: un volver. El ir al pasado como un sitio asegurado es el ansia de encontrar un refugio, aunque ese retorno idílico es a una zona que recién se construye, no es migrar a un algo que en verdad existió sino a un claustro, como el materno, ideado. Ir de vuelta al tribalismo, la desigualdad y el útero son figuras para mostrar cómo hoy se apuesta por ir a lugares conocidos, en donde las amenazas sean ínfimas y puedan ser vencidas, donde hay muros contra los caprichos e incertidumbres del mundo.

Esa categoría, como podrá deducirse, facilita la comprensión de porqué se encienden los nacionalismos, los populismos y, en general, las zonas comunes que exaltan la pertenencia a terrenos conocidos y definitorios de identidad; en esa retrotopía se encuentra la llave para abrir la puerta a la exploración de prácticas intolerantes y delimitadoras entre el nosotros frente a los otros.

La nostalgia, como parte del genoma de la propuesta de Bauman, nos permite conectar el sentimiento de pérdida con sus mecanismos de defensa (la confusión del hogar real con el imaginado) y, yendo más allá, con los fenómenos sociales actuales a los que se adosa el calificativo de "caóticos".

\section{LA SOCIEDAD DE HOY}

A riesgo de volver a andar sobre una senda ya recorrida en uno de los primeros apartados de este texto, pero con la intención de remarcar especificidades que obligan a repensar el enfoque de los análisis sociales, se hará

\section{(C) $(0 \bigcirc$}

La Revista Estudios es editada por la Universidad de Costa Rica y se distribuye bajo una Licencia Creative Commons Atribución-NoComercial-CompartirIgual 3.0 Costa Rica. Para más información envíe un mensaje a revistaestudios.eeg@ucr.ac.cr. 
una referencia muy suscita a cinco rasgos principales que circundan la idea de sociedad contemporánea.

En primer lugar, debe reconocerse una relación tensionada entre los ya citados pueblos del Estado y pueblo del mercado (Streek, 2016:83-93). Los gobiernos endeudados deben, a partir de sus políticas públicas, decidir cuánto más ceden en la retracción del control sobre el mercado; además, las liberalizaciones, exenciones fiscales en zonas francas, cambios en la política impositiva y la contención del gasto público inciden en el respaldo que se puede obtener de las entidades supranacionales que modulan las dinámicas financieras y, consecuentemente, las políticas sociales de los países.

Durante el proceso de aprobación del presupuesto 2015, el gobierno de la República de Costa Rica fue altamente criticado por aumentar las partidas destinadas a varios programas -entre ellos los sociales- en un marco de un déficit fiscal apremiante, cuestionamiento que el otrora mandatario respondió señalando: "El riesgo de un deterioro en servicios públicos esenciales, que conduzca a retrocesos en salud, educación o seguridad (...) Tampoco procede la cancelación de las inversiones que son indispensables para superar rezagos en infraestructura" (Cambronero, 2014).

En sentido opuesto, con la toma de posesión de un nuevo gabinete en el citado país centroamericano (tras las elecciones generales de 2018), vinieron propuestas administrativas y legislativas tendientes a constreñir el gasto, tras lo cual entidades internacionales mostraban su complacencia, como lo hizo ver el Semanario Universidad en la nota "Propuestas para contener el gasto son "positivas", afirma el Banco Mundial".

Lo anterior devela, como segundo rasgo, una sociedad mediada por un modelo neoliberal comandado por agencias que ya no se encuentran en los territorios nacionales y que, además, propicia un aumento en la brecha social y una baja en la participación electoral: la ciudadanía no toma partido en las

\section{(C) $(00$}

La Revista Estudios es editada por la Universidad de Costa Rica y se distribuye bajo una Licencia Creative Commons Atribución-NoComercial-CompartirIgual 3.0 Costa Rica. Para más información envíe un mensaje a revistaestudios.eeg@ucr.ac.cr. 
contiendas electorales por la pérdida de confianza en las instituciones; estas ya no solventan sus necesidades (Streek, 2016, pp. 61-63).

Como un tercer elemento, se habla de la pauperización general de las condiciones. En la modernidad regresiva la institucionalización de la precariedad es la tónica: hay un descenso de las relaciones laborales normales; la juventud y baja cualificación son factores determinantes para la ocupación típica (jóvenes más afectados por la precariedad). Lo que antes era atípico se torna normal: trabajos poco estables que inciden en la autoestima de los trabajadores (Nachtwey, 2017, pp. 107-113).

La vigorosa clase media de los años sesenta y setenta del siglo anterior, permitió un clima generalizado de bienestar en la mayoría de países del mundo Occidental: la educación entonces sí garantizaba mejoras ostensibles en las condiciones de vida de la ciudadanía y la brecha social no era tan profunda.

Sin embargo, con el pasar de los años, las modificaciones en las relaciones de trabajo y programas de ajuste estructural (como figuras típicas en América Latina) incidieron negativamente en el ingreso, capacidad adquisitiva y posibilidades de ascenso de las nuevas generaciones.

La ausencia de soportes para convertirse en un actor social independiente es la cuarta característica de la sociedad de hoy. Como puntos de apoyo se han tenido -en la época premoderna- una entidad metafísica (Dios); la propiedad privada en la primera modernidad; y, más recientemente, la ciudadanía social (como sintetizador de un período de sujetos con derechos). Empero, en la fase en la que nos encontramos, se ha despojado al individuo de bastiones, ahora está solo, de él depende el éxito o el fracaso, y los anclajes sociales se desvanecen (Castel, 2010).

Finalmente, como quinta particularidad consideramos importante enlistar a la exclusión multiforme (Castel, 2010:263, 267-268). Las reglas de los juegos social y económico impulsan la aparición de sujetos "supernumerarios", individuos que están fuera de las condiciones de la competitividad y la competencia; en 
atención a la baja en las oportunidades de empleo, no encuentran espacio en la sociedad contemporánea. Así, el nuevo orden produce exclusión en tres escenarios: a) la supresión completa de la comunidad (desterrados, herejes, sediciosos); b) la construcción de sitios cerrados, recortados de la comunidad (asilos, guetos); y, c) la negación espacios y características para coexistir en la comunidad (voto censitario, exclusión de la mujer, adultocentrismo).

\section{REFLEXIÓN FINAL}

Las nuevas situaciones suelen avivar nuestros mecanismos de defensa, la actitud conservadora frente a lo desconocido es instintiva, coadyuva a la preservación de la especie. Sin embargo, una cautela mal llevada puede desembocar en una petrificación del ánimo.

Asistimos a transformaciones aceleradas en el mundo social. El futuro ya no es el lugar aún inexistente pero largamente anhelado de antaño, las presiones político-económicas para la liberalización y la adaptación dinámicas de trabajo precarizado impacta psicoemocionalmente a los sujetos, la reconfiguración de un capitalismo tardío, dejado de las amarras del Estado que participaba en una lógica de garantizar mínimos de bienestar, toma la palestra.

Ante ello, los individuos que no se sienten parte o desfallecen ante los muros sordos del paro, los salarios a la baja, un alto endeudamiento, las obligaciones incumplidas y el deseo de ser parte de una cultura de consumo se refugian en formaciones simples, sitios supuestamente conocidos, un pasado reconstruido a cada momento.

En ese terreno las categorías tradicionales de la teoría social (sociedad, clase, estructuras, exclusión...) deben entrar en un proceso de evaluación; repensar los contenidos es necesario para garantizar la solvencia analítica. Alguien podría pensar que es mejor la táctica de Nerón: hacer arder el utillaje conceptual y comenzar desde las cenizas; empero, nos parece que esa no es la salida, total -como se explicitaba hace algunos párrafos-sigue ahí esa fuerza que

\section{(c) (i) (2)}

La Revista Estudios es editada por la Universidad de Costa Rica y se distribuye bajo una Licencia Creative Commons Atribución-NoComercial-CompartirIgual 3.0 Costa Rica. Para más información envíe un mensaje a revistaestudios.eeg@ucr.ac.cr. 
nos mueve y condiciona, quizás han cambiado su aspecto y maneras, mas la sociedad permanece ahí.

Sirva este estadio de incertidumbre como acicate para buscar los nuevos hilos que unen al individuo con lo social, para conjugar nuevos planteamientos teórico-metodológicos con los antiguos, para no desfallecer y seguir cumpliendo con la faena que, entusiastas y por decisión propia, asumimos: dar sentido y significado al mundo.

\section{BIBLIOGRAFÍA}

Alborch, C. (1999) Solas: gozos y sombras de una manera de vivir. España: Círculo de lectores S.A.

Alfaro, J. (2018) Propuestas para contener el gasto son "positivas", afirma el Banco Mundial. Nota periodística en: Semanario Universidad, sección "País", edición del 31 de mayo de 2018. Recuperado de: https://semanariouniversidad.com/pais/propuestas-para-contener-el-gastoson-positivas-afirma-el-banco-mundial/

Bauman, B. (2017) Retrotopía. Paidós.

Berger, P. y Luckmann, T. (1995) La construcción Social de la realidad. Buenos Aires: Amorrortu.

Berman, (2013) Todo lo sólido se desvanece en el aire. México: Siglo XXI.

Cambronero, N. (2014) Luis Guillermo vuelve a defender presupuesto en cadena nacional. Nota periodística en: El Financiero, sección "Economía y política", edición del 19 de octubre de 2014. Recuperado de: https://www.elfinancierocr.com/economia-y-politica/luis-guillermo-solisvuelve-a-defender-presupuesto-en-cadenanacional/YSKXUO7AIBGUXNC7Z2RBZJVQ3U/story/

Castel, R. (2010) El ascenso de las incertidumbres. Buenos Aires: Fondo de Cultura Económica.

CEPAL (2018) La ineficiencia de la desigualdad. Santiago: Naciones Unidas. Recuperado

de:

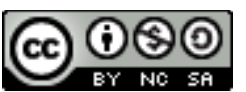

La Revista Estudios es editada por la Universidad de Costa Rica y se distribuye bajo una Licencia Creative Commons Atribución-NoComercial-CompartirIgual 3.0 Costa Rica. Para más información envíe un mensaje a revistaestudios.eeg@ucr.ac.cr. 
Revista Estudios, (37), 2018.

Diciembre 2018-Mayo 2019

ISSN 1659-3316

Cambronero Torres Andrei

https://repositorio.cepal.org/bitstream/handle/11362/43566/1/S1800302_es. pdf

Cortina, A. (2017) Aporofobia, el rechazo al pobre. Un desafío para la democracia. Paidós.

Dubet, F. (2009) El trabajo de las sociedades. Buenos Aires: Amorrortu.

Durkheim, E. (2011) Las reglas del método sociológico. Argentina: Gradifco SRL.

Kaufmann, J.C. (2015) Identidades. Ariel.

Luhmann, N. (2006) La sociedad de la sociedad. México: Herder.

Nachtwey, O. (2017) La sociedad en descenso. Paidós.

Outhwaite, W. (2008) El futuro de la sociedad. España: Amorrortu Editores.

Rex, J. (1981) Problemas Fundamentales de la Teoría Sociológica. Amorrortu

Sassen, S. (2015) Expulsiones. Brutalidad y complejidad en la economía global. Katz.

Streeck, W. (2016) Comprando tiempo. Katz.

Vallespín, F. y Bascuñan, M. (2015) Populismos. Alianza Editorial.

Žižek, S. (2008) En defensa de la intolerancia. Madrid: Sequitur.

\section{(c) (i)(3)}

La Revista Estudios es editada por la Universidad de Costa Rica y se distribuye bajo una Licencia Creative Commons Atribución-NoComercial-CompartirIgual 3.0 Costa Rica. Para más información envíe un mensaje a revistaestudios.eeg@ucr.ac.cr. 